\title{
Treatment of elderly adults with impaired hearing: resources, outcome, and efficiency
}

\author{
P. R. W A R D \\ From the Institute of Biometry and Community Medicine, University of Exeter
}

SUMMARY The general relationship between treatment and response is illustrated with reference to the response of elderly people to rehabilitation treatment after a hearing aid has been prescribed. The evidence of the effects of treatment is reviewed and a tentative empirical relationship is proposed between treatment input (therapist time) and effect (hours of use of the hearing aids). This illustrates a rapid improvement in the effect of treatment for up to about one hour of therapist time but very little improvement with increasing input thereafter. The resource implications are discussed and it is concluded that an input of an average of one hour of follow-up would be a very worthwhile investment and should be a priority for expenditure by health authorities.

Economists have suggested that it is essential to establish the relationship between input and output in the health services in order to create efficient services. ${ }^{1-3}$ Some clinicians have also been persuaded of this need..$^{4-6}$ If resources (staff, building, equipment, aids, drugs, etc.) are not to be used in treating diseases, and other conditions, beyond the point where there is any gain in benefit, it is essential to establish such relationships.

Treatment of many conditions involves knowledge or assumptions about the way people will respond. The process of diagnosis is concerned with placing a person in a category that enables the practitioner to decide which relatively standard treatment, if any, should be used. Treatment is based on the expectation of a given response, or a response within defined bounds. Underlying this expectation is knowledge or assumption about response, based on real or hypothetical treatment response functions (Fig. 1). Drug-dosage response curves are one typical family of functions on which treatments are based. ${ }^{7}$ These are production functions of a sort, where the dosage is the resource or input and the response (reduction in symptoms, say) is the output. An example pertinent to the habilitation or rehabilitation treatment procedures is the learning curve. $^{8}$ This is normally conceptualised as a time-dependent function, but it can be converted to a resource-dependent function by substituting input of instruction or instructor time for learning time.

For the purposes of this paper the important feature of the two examples is that there will always

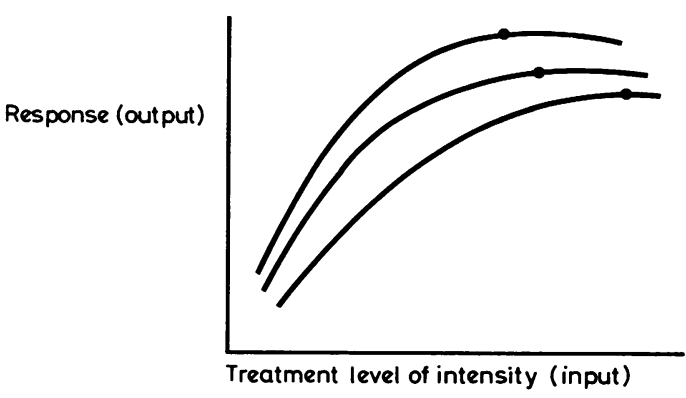

Fig. 1 Hypothetical treatment response functions.

be a plateau of performance after some given level of input (for example, A on Fig. 1). In addition, the response can be considered as that of the average or typical response to treatment of a group of individuals, which is, it has been argued, the basis of much medical practice-that is, treatment is usually standard according to diagnosis and is related to expected standard response.

In this paper an attempt will be made to derive this sort of function for the typical elderly adult patient with impaired hearing in relation to rehabilitation treatment after a hearing aid has been prescribed. The monetary value of such treatment will also be discussed. The patient is aged 60 or over with a gradual onset sensorineural $(s / n)$ hearing loss, or mixed $s / n$ and conductive loss between 30 and $80 \mathrm{~dB}$ in his or her better hearing ear with no marked abnormal loudness function. This sort of patient 
would account for at least $80 \%$ of all elderly people for whom hearing aids are prescribed by the National Health Service (and for about $64 \%$ of people of all ages so prescribed).

Where health services for people with impaired hearing are well developed, especially in Denmark, rehabilitation treatment for this group usually consists of instruction in the fitting, care, and use of the hearing aid. ${ }^{9-11}$ The follow-up service is provided by staff with teaching experience who reinforce the instruction received when the aid is fitted. Until recently the services in Britain had been neglected but new staff are being trained to provide a more effective follow-up service as recommended by the Advisory Committee on Services for Hearing Impaired People. ${ }^{12}$ This committee stated that the service proposed was in no way experimental but would fill a substantial gap in services. However, no evidence of the effectiveness of the proposed service was offered, nor was it intended that the routine follow-up service would be provided for elderly people by these new staff. This was to be provided by the technicians who fit the aids. ${ }^{12}$ It is not my intention to discuss here the wisdom of the committee's recommendations; the effectiveness of different amounts of follow-up service to elderly people is the main concern. The technicians each fit about four to five aids per week and they also have to service clinics for tests of auditory function, as well as providing a repair and maintenance service for aids. With increasing pressure on technicians' time for auditory tests, it is important to determine what is the optimum follow-up service.

\section{REVIEW OF EVIDENCE}

Typically, hours of use of hearing aids has been taken as indicative of the effectiveness of treatment. Here, the purpose of treatment (hearing aid and follow-up) is taken to be the reduction of the handicap experienced as a result of a hearing loss. Ideally, a measure of this should be the criteria of effectiveness, but few research workers have used it. ${ }^{13-15}$ Consequently, the measure of output concentrated on is hours of use. The relationship between the two measures has not been reported in the literature. However, it is likely that increased use of the aid, and especially reduction in non-use, will result in reduced auditory handicap.

Brooks ${ }^{15}$ and Stephens ${ }^{16}$ have pointed to the differences between rates of use of hearing aids in Denmark and in this country as an indication of the effect of their follow-up services. In the latter paper it was suggested that the level of use of hearing aids was connected with the sophistication of the rehabilitation programmes. We can interpret the results of this review as supporting the argument that the level of input of rehabilitation services determines the use made of hearing aids (within limits). However, the relationship of the level of input to the level of response cannot be gleaned from it, nor is the description of the level of input usually available in the published work. Birk-Nielsen and Ewertsen $^{13}$ demonstrated improvements resulting from hearing aids and follow-up services, but they did not estimate the effects of the follow-up services separately. Aasen ${ }^{17}$ found that use of hearing aids by patients receiving some follow-up treatment was significantly higher than use by untreated patients. Brooks $^{18}$ has also reported that with treatment the non-use of body-worn OL56 aids was reduced from $30 \%$ to $3 \%$ but that the overall level of use (hours per day) was low. He reports a modal value of one and a half hours for the treated group and one hour for the untreated group. However, he has found that the NHS new head-worn BE Series aids have a much higher level of use, and this is confirmed by other workers, ${ }^{19} 20$ although without any follow-up service the non-use of these aids is still about $30 \%^{14} 21$

The rehabilitation service evaluated by Brooks $\$$ consisted of a minimum of three visits by volunteers one within 10 days of the fitting of the aid, and thep other two at one month and three months] approximately. The first visit concentrated ong handling and care of the aid. During the other two @ visits the main emphasis was on encouraging moreo $\frac{\rho}{\sim}$ extensive use of the aid. ${ }^{15}$ The total contact time was. $\overrightarrow{0}$ not reported but it was probably approximately one and a half to two hours. A group provided with a follow-up service lasting for 30 minutes at two weeks after their NHS BE aids were fitted showed significant improvements compared with a group for whom no such service was provided. ${ }^{22}$ In an earlier experiment no differences were apparent in groups who had two hours of contact at the time the aid was fitted compared with those who had an additional four or eight hours of follow-up. In the latter experiment the rate of occasional or non-use was very low (about 3\%) whereas in the former it was much higher (about $20 \%$ in the treated group). In Denmark, where the basic follow-up service is variable, but probably on average about one hour, ${ }^{16}$ the rate of use is fairly high among the elderly patients. ${ }^{23}$ The results from some of these studies are summarised in the Table. If these data are plotted they appear to indicate a very large improvement in use for small increases in service input (Fig. 2). The improvements are not as dramatic for higher levels of input. Naturally these results are very tentative because they involve many assumptions about results from different studies.

Follow-up services generally attempt to help a person to fit the earmould and aid to his ear, to 
Table Summary of findings of surveys of use of aids compared with time of rehabilitation programme

\begin{tabular}{|c|c|c|c|}
\hline Source & Time of follow-up & $\begin{array}{l}\text { Average hours } \\
\text { of use of aids }\end{array}$ & $\begin{array}{l}\text { No use or } \\
\text { occasional } \\
\text { use } \%\end{array}$ \\
\hline Aasen $^{17}$ & $\begin{array}{l}8 \text { hours } \\
\text { No programme }\end{array}$ & $\begin{array}{l}7 \cdot 2^{+} \\
5 \cdot 6^{+}\end{array}$ & $\begin{array}{l}4 \\
7\end{array}$ \\
\hline Ewertsen ${ }^{23}$ & 1 hour or more & $6 \cdot 8^{+}$ & 14 \\
\hline Ward et al. ${ }^{22}$ & $\begin{array}{l}2 \text { hours or more } \\
1 \text { hour programme } \\
\text { No programme }\end{array}$ & $\begin{array}{l}6 \cdot 4 \\
6 \cdot 2 \\
3 \cdot 9\end{array}$ & $\begin{array}{r}3 \\
20 \\
30\end{array}$ \\
\hline
\end{tabular}

+ Assuming that always $=12$ hours per day, often $=5$ hours, sometimes $=2$ hours, seldom or never $=0$ hours.

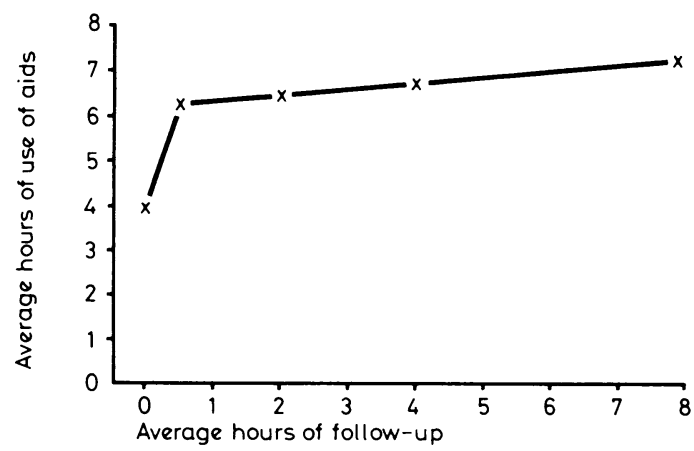

Fig. 2 Average hours of use of hearing aids in relation to average hours of follow-up service received.

become competent in the basic care of the aid (changing the battery, keeping the aid clean, and so on) and in the hearing tactics for using the aid. The skills involved in the first two are basically mechanical but the latter involves teaching new social skills. These skills are concerned not only with the behaviour of the person with impaired hearing but also with the behaviour of others (for example, their faces should be well lighted, they should speak more slowly, etc.). These skills are thus substantially more complex than the fitting and care skills. Consequently it is more difficult to test whether people have acquired these social skills than to test their ability in mechanical skills. In addition, the mechanical skills need to be acquired before the social skills can be practised. Experience in experimental programmes indicates that acquisition of the mechanical skills is essential for effective use of hearing aids. ${ }^{22}$ Where no follow-up service is provided, difficulty with fitting the earmould is the most common problem found. ${ }^{14-1524}$ Tasks involved in caring for the aid are also commonly misunderstood. ${ }^{22}$ Effective methods of teaching these have been demonstrated..$^{25}$

The evidence of the effects of teaching hearing tactics is not available. Measurement is made difficult by the nature of the skills, and practice for old people will be inhibited in many cases by their life-style. Acclimatisation to the aid can occur only by wearing it; if a person can hear better with it he will generally become acclimatised at his own pace and adopt tactics which are found useful. But the tangible skills of handling and care are a necessary first step for this.

However, it should be emphasised that a universal follow-up service of one hour will not be sufficient for a significant minority of patients even in the restricted group considered here. My own estimate from current research is that at least $25 \%$ will require more than one hour and three-fifths of these will require substantial help. The evidence of the research reviewed above is that non-use can be reduced to about $5 \%$ (from $15 \%$ ) if follow-up is increased from one hour to two or more, although this should be provided only for those who need it. A universal follow-up service for elderly people which concentrates on teaching basic mechanical skills would appear to be most effective. Additional input should be concentrated on those who are not using their aids, or who have difficulty, by providing further training in these skills. This will not be effective with all of this group but further research is required in defining effective programmes for them.

\section{RESOURCE IMPLICATIONS}

The implication of Fig. 2 is that patients will achieve the largest part of an improvement in the use of their aids with an average of between half an hour and two hours of follow-up. An average of one hour will probably be adequate, but some will need more, some less. For the National Health Service this implies a modest increase in input of manpower overall above the current level. For example, in a hearing aid centre with about 500 new patients per year (with a catchment population of about 250000 ), something like three half-day sessions per week would be sufficient for the additional follow-up procedures required for elderly new patients. Average staffing levels in a district with this size of load would be 24.5 sessions approximately (based on the number of PMT(A)s in England in 1977-451) and the increase in staffing levels proposed is about $12 \%$. If the gross cost of a technician per annum is $£ 5000$ then the follow-up service would cost $£ 1500$ using a person of technician status. Assuming the service reduces non-use by $50 \%$ (that is, non-use falls to $15 \%$ ), it would prevent the non-use of 75 hearing aids per annum. If non-use were regarded as a cost to the community equivalent to the cost of a hearing aid (at say $£ 25$ each), $£ 1825$ per annum would be saved. This can be regarded as a minimum gross benefit.

The benefits of the aid derive from its effects on the individual's ability to communicate and hence on the 
quality of his life. Exact monetary values cannot easily be derived for these benefits. As part of an evaluation of rehabilitation services ${ }^{22}$ people were asked what value they put on the benefit of their hearing aids. Some said 'priceless' or 'you can't measure it in money terms'; however, nearly all of them ( 38 out of 42 ) did indicate a value of the aids, ranging from $£ 10$ to $£ 400$. The average was about $£ 75$. For the 75 people who would use their aids as a result of the rehabilitation programme, this figure would give a benefit of $£ 5625$ at our hypothetical centre. This must be regarded as less than the maximum because a rehabilitation programme would also encourage greater use of hearing aids overall. More than 60000 aids are prescribed each year to new patients in England and Wales. If each patient received one hour of follow-up the additional resources required would be equivalent to 35 full-time posts at $£ 5000$ per annum gross, making a total cost of $£ 175000$. About 9000 aids worth $£ 25$ would be 'saved', giving a gross benefit of $£ 225000$ and a minimum net benefit, excluding benefits of increased use of hearing aids, of $£ 50000$ per annum. If benefits of using the aid to the patients who would otherwise not use it are again taken as an average of $£ 75$, then the gross benefit would be $£ 675000$, giving a net benefit of $£ 500000$. These levels of return for the investment in rehabilitation services look very attractive, especially as the absolute level of increase in resources is low.

\section{Conclusion}

As the level of resources required to achieve near maximum response is relatively low, and the returns on this modest investment high, health authorities should give priority to providing a basic follow-up service for elderly users of hearing aids. It is essential that the service should concentrate on handling and care of the aids and that it should be backed up by effective teaching of these skills from the time when the hearing aid is first fitted.

The way in which follow-up service can be provided at any centre needs to be examined in the light of local circumstances. Some centres use volunteers, some professional staff. The crucial first stage is local commitment to provide the service.

Reprints from Mr. P. R. Ward, University of Exeter, Institute of Biometry and Community Medicine, Bowmoor House, Barrack Road, Exeter EX2 5DW.

\section{References}

${ }^{1}$ Culyer AJ, Lavers RJ, Williams A. Social indicators: health. Social Trends 1971; 2: 31-44. London: HMSO.
${ }^{2}$ Williams A. Measuring the effectiveness of health care systems. Br J Prev Soc Med 1974; 28: 196-202.

${ }^{3}$ Pole D. Programmes, priorities and budgets. Br J Prev Soc Med 1974; 28: 191-5.

'Cochrane AL. Effectiveness and Efficiency: Random Reflections on Health Services. London: Nuffield Provincial Hospitals Trust, 1971.

${ }^{5}$ Bunker, JP, Barnes BA, Mosteller F. Costs, Risks and Benefits of Surgery. New York: Oxford University Press, 1977.

${ }^{6}$ Dudley HAF. Economics of surgery. J R Soc Med 1978; 71: 397-8.

${ }^{7}$ Stephenson RP, Barlow RB. Concepts of drug action, quantitative pharmacology and biological assay. In: Passmore R, Robson JS, eds. A Companion to Medical Studies. Vol. 2 Pharmacology, Microbiology and General Pathology and related subjects. Oxford: Blackwell, 1970.

${ }^{8}$ Houston JP. Fundamentals of Learning. New York: Academic Press, 1976: 121.

${ }^{4}$ Ewertsen HW. Theoretical considerations and practical experience in hearing aid selection. Sound 1967; 1: 92-7.

${ }^{10}$ Lundborg T, Linzander S, Rosehamer H, Lindstrom B, Svaro I, Fransson A. Experiences with hearing aids in adults. In: Lundborg $\mathrm{T}$, ed. A symposium on he?ring aids. Scand Audiol 1973; 3: 9-46.

${ }^{11}$ Markides A. Rehabilitation of people with acquired deafness in adulthood. Br J Audiol 1977; Supplement 1.

${ }^{12}$ Department of Health and Social Security. Report of a Sub-Committee to Consider the Rehabilitation of Hearing Impaired Adults. London: DHSS, 1975.

${ }^{13}$ Birk-Nielsen H, Ewertsen WH. Effect of hearing aid treatment. Scand Audiol 1974; 3: 35-8.

${ }^{14}$ Ward PR, Morgan DC, Gowers JI. Problems with Handling the BE10 Series Hearing Aids. Final Report. Exeter: Institute of Biometry and Community Medicine of the University of Exeter, 1978.

${ }^{15}$ Brooks DN. Hearing aids for adults. Hearing 1976; 13 (4): $122-4$.

${ }^{16}$ Stephens SDG. Hearing aid use by adults: a survey of surveys. Clin Otolaryngol 1977; 2: 285-402.

${ }^{17}$ Aasen A. Undersokelse i bruken av horsapparater. Nord Audiol 1970; 19: 19-24.

${ }^{18}$ Brooks DN. Some features of people obtaining National Health Service aids. Paper given at British Society of Audiology meeting, London, January 1979.

${ }^{19}$ Newall, P. A survey of adult patients fitted with National Health Service aids. Paper given at British Society of Audiology meeting, London, January 1979.

${ }^{20} \mathrm{Haggard} \mathrm{M}$. Hearing of older people. In discussion at British Society of Audiology meeting, London, January 1979.

${ }^{21}$ Brabbins M, Hogg L. 'What did you say?' The use and misuse of hearing aids by the elderly. London: Kensington, Chelsea and Westminster (South) Community Health Council, 1977.

${ }^{22}$ Ward PR, Tudor CA, Gowers JI, Morgan DC. Evaluation of follow-up services for elderly people prescribed hearing aids. Report of a pilot project. BrJ Audiol 1978; 12: 127-34.

${ }^{23}$ Ewertsen HW. The use of hearing aids (always, often, rarely, never). Scand Audiol 1974; 3: 173-6.

${ }^{24}$ Oswal VH. The National Health Service and social services link-up for rehabilitation of hearing aid users. Br J Audiol 1977; 11 (1): 25-30.

${ }^{25}$ Ward PR, Gowers JI. Fitting hearings aids: the effects of methods of instruction. Br J Audiol 1979; (In press). 